\title{
An investigation into the effectiveness of public entities' procurement practices
}

\begin{abstract}
Authors:
Moitswadi Mofokeng

Rose Luke ${ }^{1,2}$

Affiliations:

${ }^{1}$ Department of Transport

and Supply Chain

Management, University of

Johannesburg, South Africa

${ }^{2}$ Institute of Transport and Logistics Studies (Africa)

University of Johannesburg, South Africa
\end{abstract}

\section{Correspondence to:}

Rose Luke

Email:

rluke@uj.ac.za

Postal address:

PO Box 524, Auckland Park

2006, South Africa

Dates:

Received: 15 Mar. 2014

Accepted: 15 Aug. 2014

Published: 21 Nov. 2014

How to cite this article: Mofokeng, M. \& Luke, R., 2014, 'An investigation into the effectiveness of public entities' procurement practices', Journal of Transport and Supply Chain Management 8(1), Art. \#136, 7 pages. http://dx.doi. org/10.4102/jtscm.v8i1.136

\section{Copyright:}

(C) 2014. The Authors.

Licensee: AOSIS

OpenJournals. This work

is licensed under the

Creative Commons

Attribution License.
Read online:
The delivery of services through the procurement of goods and services requires proper strategic leadership and management processes. Inappropriate planning, under-spending of budgets and ineffective procurement form part of the root causes of poor service delivery, as this restricts the movement of resources to the right places. This study identified the leading procurement practices as: procurement strategy and leadership, the procurement process, human resource management, procurement information systems, supplier management and procurement performance management. These practices were then tested in public entities, mainly in Gauteng Province, South Africa, to determine the extent to which they are applied. The study found that there is a major divide between the perception of the level of application of the leading practices and actual implementation. Processes, skills, performance management, information technology (IT) systems and supplier management are applied inadequately or inappropriately. Most entities thus show a poor understanding of customer needs and there seems to be a general lack of customer focus. The study highlighted the best practice areas in which public entities are able to focus their efforts to better achieve excellent customer service and thus service delivery.

\section{Introduction}

There have been frequent reports in the media over the past few years of community protests about poor service delivery. The reasons for these include lack of transparency, communication and accountability, corruption, maladministration and financial mismanagement (Akinboade, Kinfack \& Mokwena 2012; Mofolo \& Smith 2009). Inappropriate planning, under-spending of budgets and ineffective procurement form part of the root causes of poor service delivery to the public, as this restricts the movement of resources to the right places (Taylor, Fleisch \& Shindler 2008). The Constitution of the Republic of South Africa (Republic of South Africa 1996) states that the procurement system should be fair, equitable, transparent, competitive and cost-effective. Consequently, the Public Service Commission has a code of conduct to which public sector employees must adhere and the National Treasury, through its Supply Chain Management Unit, administers procurement legislation (National Treasury 2003a) and provides support to public entities.

Despite this, there is a lot of negative publicity regarding public sector procurement practices. The public does not trust the public sector procurement process (O'Regan 2012) and the Auditor General's report (2008) indicates that public sector procurement processes are unlikely to enable the achievement of the constitutional procurement goals. Proper procurement management practices in public entities will lead to better public service delivery, reduction in resource waste and increased public wealth. The purpose of this research is to test the extent to which public entities apply leading procurement practices.

\section{Literature review}

Procurement is a series of activities necessary for the timely acquisition of goods and services, to satisfy user requirements and fulfil organisational goals. Procurement activities should be directly linked to organisational goals, management plans and stakeholders' expectations (Schapper, Malta \& Gilbert 2006). Procurement thus seeks to acquire high quality goods and services to satisfy customer requirements; efficiently and cost effectively.

To identify the primary objectives of the procurement process, a literature review was conducted which included the Constitution of South Africa (Republic of South Africa 1996). Although not all sources described preferential procurement, this was included as analysis of public procurement processes in South Africa would be incomplete without this. To identify those procurement goals which were applicable to the public sector, procurement was firstly considered from a generic perspective. Only those objectives that were relevant to the public 
sector were retained. The literature review then focused exclusively on public sector procurement. The results of these analyses were merged and the main goals of public sector procurement identified. These are described below:

- Value for money implies the maximisation of benefits and minimisation of payment when procuring services and products (Raymond 2008). Customer satisfaction should be emphasised when evaluating value for money (Schapper et al. 2006).

- Public procurement involves the spending of public funds and it is critical for procurement officers to act in the public interest (Hunsaker 2009). This is supported by government's 'Batho Pele' principles (Department of Public Service and Administration 2007).

- Competition occurs when a public entity invites all bidders and clearly describes the required services and evaluation criteria. A competitive environment will lead to price reduction and improved quality of service (Raymond 2008).

- Transparency refers to the openness of the bidding process, so that every step is open to public scrutiny. This promotes good governance and accountability. It also builds confidence amongst stakeholders (Hazlett, Johnston \& McAdam 2011).

- Accountability represents an obligation to answer for actions (Gray \& Jenkins 1993). It increases the quality of decisions as officials are aware that there are repercussions for poor or negligent decisions. Entities that are accountable to their stakeholders are more responsive to their needs (Huque 2011).

- Fair procurement implies procurement that is impartial, free from discrimination, just and complies with laws and policies (Pauw \& Wolvaardt 2009). Where fair treatment is not applied, service providers may not submit tenders and entities are thus deprived of services that could have been more efficient and cost-effective (International Transport Forum 2008).

- The Constitution (Republic of South Africa 1996) and the General Procurement Guidelines (National Treasury 2003b) allows any organ of state to give preference in the allocation of contracts to previously disadvantaged persons. Service providers that do not qualify for preferential points may partner with qualifying providers, which should result in the development of previously disadvantaged service providers.

These seven objectives are regarded as critical to the success of the procurement function within public entities. To achieve the procurement objectives, appropriate procurement practices must be applied. In South Africa, procurement processes are prescribed by law, as is discussed below under the heading 'Research method and design'. Whilst this promotes uniformity in the public sector procurement practices, it does not necessarily guarantee excellence or even success. To achieve this, it is critical that the public sector complies with practices that are regarded as promoters of excellence within the procurement function.
The leading procurement practices were established through a comprehensive literature review and are described below.

\section{Procurement strategy and leadership}

A strategy is a planning process which outcomes include goal and action definition, the allocation of responsibilities and resources, timeframes for implementation and performance controls (Goncalves 2009). This should be aligned to customer requirements (Shipley \& Kovacs 2008). Management should view the procurement function as a strategic asset and not an administrative function and should support it appropriately (US Government Accountability Office 2009). The procurement strategy should contribute to effective and efficient attainment of business objectives (Baldwin, Orr \& Simon 1996).

\section{The procurement process}

A process is a set of activities that, when performed collectively, will result in the achievement of business goals by converting specified input to the desired output. Procurement processes should be focused on delivering goods or services effectively (Baldwin et al. 1996). Processes provide the flow of information and decision points within the organisation. They also indicate the roles and responsibilities of employees (US Government Accountability Office 2009). Processes should focus on customer needs.

\section{Human resource management}

The purpose of human resource management is to attract, develop and fulfil employees, whilst they execute the business strategy. Human resource management should support the entity's strategic goals. The organisation has to assess its human resources needs and set initiatives to ensure that skills are available to match strategy requirements (Baron 2011).

\section{Procurement information systems}

The information technology (IT) system provides an organisation with capabilities to capture, store and manipulate business data and serves as an internal communication tool (Mehrjerdi 2009). It provides an opportunity to review processes and eliminate redundancies (Amaratunga, Sarshar \& Baldry 2002). The use of IT will assist entities to make decisions that support organisational goals.

\section{Supplier management}

Supplier management is a series of coordinated activities to select suitable suppliers to enable the achievement of the entity's goals. The supplier and the entity need to have a common purpose, which requires a mutual working trust (Chi, Pun \& Yeung 2006). The supplier's contract should have objectives, outcomes, costs, delivery schedules, nonperformance penalties and the reporting process (US Government Accountability Office 2009) and should be used to manage the supplier's performance.

\section{Procurement performance management}

Performance management is a process to detect and alter performance that does not meet the standards set at strategic 
and operational planning stages (Novack, Dunn \& Young 1993). The purpose is to provide a link between strategic goals and outcomes (Defee \& Stank 2005). The performance management system is a diagnostic tool for problems and provides an early warning system (US Government Accountability Office 2009).

\section{Research method and design}

The leading procurement practices identified in the literature review were then tested in the public sector to determine the extent to which these were being applied in public entities. The study focused on public entities mainly in Gauteng Province, firstly, to minimise research costs and, secondly, because, as South Africa's economic hub, most entities are based there and could thus be considered as relatively representative the population.

In 2003, the government issued a policy strategy to guide uniformity in procurement reform. This included standard procurement objectives and procurement officers' expected behaviour (National Treasury 2011). One of the objectives was to promote uniformity in bid procedures (National Treasury 2003a). National Treasury also maintains a Chief Financial Officers (CFOs) Forum to promote consistency and competency in procurement management. Public entities are regulated primarily by the Public Finance Management Act (Act No. 1 of 1999) (Republic of South Africa 1999) and obtain further guidance from National Treasury guidelines (National Treasury 2012).

As they all use the same procurement procedures, the population of public entities is regarded as homogenous. A small sample of $5 \%$ (24 public entities) was used as this is appropriate where the population is largely homogeneous (Zikmund 2003). The size of the sample does, however, imply that the outcomes should be regarded as indicative of procurement practices within public entities and not absolutely representative.

The research methodology used for the study was based on a quantitative methodology in terms of sampling and questionnaire design. As indicated above, the small sample size means that results should be regarded as exploratory and not representative of the population. The survey instrument comprised structured questions which tested, on a Likerttype scale, the extent to which public entities complied with the leading procurement practices. The questionnaire for this study was sent to the CFOs of the sampled entities as the procurement function falls under their office (National Treasury 2004). The statistical analysis method used was exploratory data analysis (EDA), which is suitable for this type of research as it assists in revealing important trends in the data.

\section{Results}

The results of the survey process are presented below. Following presentation of the demographic information, the results are discussed in accordance with the leading procurement practices, as identified in the literature review.

\section{Demographic information}

Demographic information collected in the survey process reveals that CFOs generally have university degrees and $75 \%$ have over 10 years' experience. However, $75 \%$ have spent less than 5 years with their current public entity. Therefore, CFOs could possibly not have adequate experience in their current entities, which could impact their ability to perform their functions appropriately, thus impacting the entities' performance.

\section{Leadership}

The survey tested leadership in terms of application of a code of conduct, application of the leading procurement objectives, cooperation within the organisation, impact on customers and stakeholders and access to leadership structures. The majority of respondents $(67 \%)$ indicated that their entities monitored their code of conduct, thus recognising it as an important management tool. However, only $54 \%$ communicate it to employees and only $58 \%$ discipline employees for breach of the code. Management actions regarding the code appear to be inconsistent and are thus unlikely to be effective.

The majority of respondents (58\%) indicated that their senior management leads by example. This figure is low as management actions directly influence employee conduct. A large majority of respondents indicated that senior management applies the procurement objectives of transparency, value for money, ethical conduct, competition, fair process, accountability and preferential procurement. However, only $52 \%$ of respondents indicated that their entities' goals are based on customer input, which could indicate that they are unlikely to achieve the value for money objective, as they are unaware of their customer's requirements.

A large majority indicated that their employees have easy access to senior management. This contradicts a finding on strategic planning, where $50 \%$ of respondents indicated that they do not involve their staff when they develop strategic plans. Under customer focus, $29 \%$ indicated that they do not have a formal process to capture feedback from customers, employees and other stakeholders. Although respondents indicated high levels of employee involvement, further investigation revealed that it is largely ineffective, potentially leading to poor employee performance.

The majority of respondents indicated that senior management promotes cooperation between departments, thereby recognising the role that procurement plays in fulfilling other departments' requirements. However, under performance management, only $37 \%$ respondents indicated that other departments formally evaluate the services received from the procurement department. Real cooperation thus appears unlikely.

The majority of respondents $(66 \%)$ indicated that senior management promotes cooperation between different staff levels, thereby recognising the importance of teamwork 
in enabling the strategy. However, only 50\% of entities involve employees from different levels in their strategic planning processes. It seems unlikely that management is promoting effective staff cooperation.

Even though respondents indicated the importance of leadership by assessing it as the second-most important of all the leading procurement practices (shown in Table 1), its application appears to be inconsistent.

\section{Strategic planning}

Respondents believe that their entities are generally applying strategic planning elements. A large majority of respondents indicated that they monitor all their business's key performance indicators. Despite this, only $54 \%$ of entities achieved their targets for the 2011 financial year. The balance monitored indicators but did not appear to be successful in resolving issues that prevented them from achieving their goals.

The majority of respondents indicated that their strategic goals are not based on customer input. This will result in poor service delivery and a waste of public resources. This is supported by a finding on leadership practices, where a small majority indicated that they monitor their impact on customers. Public entities appear to be largely oblivious of their role in serving their customers.

The respondents are equally divided on employee involvement when developing strategic plans. The failure to involve employees could result in disengaged employees who do not understand their role in the entity and are therefore unlikely to perform as required. Employee involvement is critical, as only $39 \%$ of respondents indicated that their employees understand their role.

Half the respondents indicated that their entities involve the procurement team when developing their strategic plans. This low level may result in misaligned procurement plans and ultimately in poor performance. The majority of respondents indicated that their procurement strategy supports the overall business strategy. However, only 29\% of the respondents formally evaluate feedback from customers. The majority of respondents indicated that their procurement budget is based on strategic goals, but funds may be spent inappropriately as goals are not based on customer input.

A large majority of respondents indicated that they apply the leading strategic planning practices, but there

TABLE 1: Ranking of leading procurement practices within public entities in Gauteng Province, South Africa.

\begin{tabular}{lc}
\hline Leading procurement practices & Ranking \\
\hline Process management & 1 \\
Leadership & 2 \\
Strategic planning & 3 \\
Human resource management & 4 \\
Customer focus & 5 \\
Performance management & 6 \\
Supplier relationship management & 7 \\
Procurement information systems & 8 \\
\hline
\end{tabular}

is inadequate involvement of customers, employees and procurement teams in the process. Strategic planning is ranked as the third-most applied procurement practice; however, contradictions in responses seem to imply that strategic planning practices are unlikely to be effective.

\section{Customer focus}

Most respondents indicated that their senior management takes customer and stakeholder needs seriously. In leadership, however, just over $50 \%$ indicated that management monitors their impact on customers. In strategic planning, a majority indicated that their strategic goals are not based on customer inputs. In performance management, entities indicated that they do not evaluate customer feedback on procurement processes. A minority indicated that they have formal processes to capture feedback from customers, employees and other stakeholders. Although respondents believe that they take customer needs seriously, the application of this practice does not appear to be as stringent as the response implies.

A minority of respondents indicated that they have formal processes to capture feedback from customers, which indicates that customer needs are not necessarily incorporated into the strategic plan. A minority of respondents indicated that their performance metrics include a customer component, indicating a lack of awareness of the importance of customer service as part of overall service delivery. Strategic planning could be ill-considered, as goals are not generally linked to customers' needs.

The majority of respondents indicated that senior management reviews their plans and performance. However, only $29 \%$ of the respondents indicated that their performance indicators have a customer component and only $54 \%$ entities have achieved their business targets for 2011. This indicates that review processes are probably not robust enough to effectively influence service levels.

The majority of respondents indicated that management takes corrective action when customer needs are not met. However, almost half of the respondents have not taken customer needs into account and are therefore unlikely to be able to take corrective action. This inconsistency is further demonstrated by the poor performance results for 2011, which could indicate the entities not taking appropriate corrective action.

Customer focus practices is ranked as the fifth-most applied practice; however, it should be first as public entities exist only to serve customer needs. Most entities show a poor understanding of customer needs and there seems to be a general lack of customer focus.

\section{Process management}

A large majority of respondents indicated that their procurement processes are well defined and documented. The majority of respondents indicated that procurement objectives can be measured and that they have internal controls. Other 
findings contradict this, such as $37 \%$ that indicated that other departments evaluate their services, whilst 37\% indicated that senior management evaluates them and $29 \%$ indicated that their entities formally evaluate feedback from customers. Despite indications that their procurement processes are reviewed at least annually for the purpose of continuous improvement, the lack of appropriate review processes indicates a limited drive for continuous improvement.

A large majority of respondents $(67 \%)$ indicated that senior management takes corrective action where procurement processes are contravened. This is somewhat contradicted by a finding on leadership, where only 53\% indicated that management disciplines employees for inappropriate conduct.

A small majority of respondents indicated that their employees are trained on their procurement processes. On strategic planning, employee understanding of their role regarding strategy was assessed as low. That employee training is not a priority indicates that there is probably inadequate coordination between planning, leadership and human resource management and organisational performance.

Process management is the most applied procurement practice; however, the findings from other categories indicate that implementation is inconsistent and may not be as critical as indicated.

\section{Human resources}

Respondents indicated that there is generally an inconsistent application of the leading human resource management practices. Only half indicated that their procurement department has a human resources plan, which should outline the required skills and competencies. Training and recruitment does not seem to be linked to the procurement strategy and ultimately to the needs of the organisation. A small majority of respondents $(58 \%)$ indicated that procurement staff is recruited based on the skills and competencies required by department. This is low and also appears overstated, as only $50 \%$ have a resource plan.

A minority of respondents indicated that their staff is empowered to be innovative and improve procurement activities. This assessment is corroborated by findings on leadership, where $50 \%$ indicated that they do not involve employees in their strategy development processes. Problem solving and innovation from employees does not seem to be encouraged.

The majority of respondents indicated that their staff understands their procurement strategy. In strategic planning, respondents assessed employees' understanding of corporate strategy as very low. A small majority of respondents indicated that their employees understand their performance indicators. This indicates that employees are not always aware of their responsibilities and are therefore unlikely to be able to perform their tasks effectively. A small majority of respondents indicated that their training is based on skills requirements.
Human resources management is the fourth-most applied procurement practice, which is of concern when considering the importance of skills in effectively implementing procurement practices.

\section{Information technology management}

The majority of respondents assessed their entities to be relatively ineffective regarding the application of leading IT practices. A minority of respondents (37\%) indicated that management uses the information system to evaluate procurement performance. This figure could be even lower, as only $29 \%$ indicated that they track procurement performance information. Entities do not seem to have appropriate systems to track procurement data.

A minority of respondents indicated that management makes funding available to improve their system capacity, thereby showing that they do not necessarily use IT to improve the procurement function; they are possibly lagging in implementing appropriate technology and they do not seem to view the procurement function as a strategic partner to the organisation. Almost half the entities' data is not reliable and therefore reporting could be misleading and management could make critical decisions based on incorrect information.

A minority of respondents indicated that their employees have easy access to reports to evaluate their own and their department's performance. This indicates that employees are not empowered and is aligned with other findings which show relatively low levels of employee involvement.

A minority of respondents indicated that management's performance is measured on the quality of the reports and system reliability, indicating that IT is not generally viewed as a strategic tool and the use of procurement information is limited. IT practices are the least applied procurement practice.

\section{Management of suppliers}

Supplier management practices appear to be ineffective in public entities. A minority of respondents indicated that their suppliers are regularly informed of the entity's code of conduct, showing that suppliers may not be aware of the conduct they should expect from the entities employees and the conduct expected of them. The entities' communication with its stakeholders seems to be poor and ineffective. This is corroborated by a finding on leadership where the same issue was tested.

A small majority of respondents indicated that their suppliers' performance is monitored against contracted standards. A minority of respondents indicated that suppliers that do not meet contract performance standards are not paid. Only $20 \%$ of the respondents indicated that they would prosecute suppliers for poor performance and only $41 \%$ would remove non-performing suppliers from their database. There is little positive action for contract standards not being met. Supplier management is the second-least applied leading procurement practice. 


\section{Performance management}

Respondents indicated that performance management is the third-least applied procurement practice. The majority indicated that their department measures its performance against its strategic goals. They also indicated that they have a reward system that recognises excellent performance, demonstrating that employees are motivated to deliver high quality services. However, in 2011, only 54\% of entities achieved the goals they set at the beginning of that year, showing that overall performance is relatively low and performance measurement is not generally used to modify behaviour. Respondents do not seem to be aware of the linkages between performance measurement and delivering on goals. This contradicts a previous finding which reflected that entities effectively monitor all performance indicators.

A minority of respondents indicated that other departments formally evaluate the services received from procurement department, indicating poor interdepartmental cooperation, which was rated as high under leadership. A minority of respondents indicated that management formally evaluates the procurement department's services, indicating a lack of support and a lack of awareness of the value of procurement in service delivery. A minority of respondents indicated that they evaluate feedback from customers on procurement processes. This finding supports previous findings on low levels of customer focus.

A minority of respondents indicated that they report their reasons for not achieving their goals and implement corrective action. Indications are that the procurement function is generally not held accountable for non-performance.

\section{Conclusion}

The results from the survey indicate that the public entities are not consistently applying the leading procurement practices. The three most applied leading procurement practices appear to be process management, leadership, and strategic planning. However, this is misleading as there are numerous inconsistencies in the responses when comparing related questions in different categories. This could be the due to the possibility of bias, as most questions where respondents had to evaluate senior management actions were assessed as being effectively applied. However, assessment of similar elements where it does not overtly relate to management performance is low. As shown above, Table 1 provides a summary of the ranking of the extent of application of the leading procurement practices. This was based on the number of positive responses received for each element.

Customer focus is ranked fifth, but as this represents the entities' primary reason for existence it should be ranked the highest. This practice appears to be poorly applied and public entities need to interact more with their customers and ensure that skilled personnel form part of the drive to improve customer focus. Two of the most applied leading practices, leadership and strategic planning, should be focused on customers and not only on internal matters. Understanding customers' needs will enable improved service delivery. Even though process management is ranked the highest, contradictory findings indicate that these processes are not necessarily effective. The entities should improve their customer focus so that the right processes deliver the right services or goods at the right time to the right customers.

Public entities deliver service through employees. Therefore, more needs to be done to involve employees and equip them with skills to fulfil customer needs rather than just to meet basic legal requirements. The public deserves value for money for public goods and services. There generally seems to be fairly low levels of contract and employee performance management. These two practices constitute the service delivery machinery and yet the systems and processes to manage this are amongst the least applied procurement practices.

Supplier management is also one of the least applied leading practices. The majority of supplier contracts are not monitored and entities frequently make payment for service before verification of quality or goods and services. The impact includes a waste of public funds because of substandard service delivery, resulting in a failure to meet customer needs and negative public perception on the ability to deliver services.

The public entities do not appear to recognise the potential that IT provides, as they do not adequately use it to optimise their processes; IT is not recognised as a strategic tool. Suitable IT tools will contribute to improved productivity, performance and service delivery.

This study sought to identify whether best procurement practices were being applied within South Africa's public entities. It did not seek to determine the reasons why these practices were not applied or poorly applied. Thus, there are opportunities for further research to determine the root causes for not applying these practices and identifying interventions that management should implement to address these shortcomings. Opportunities also exist for research to be conducted to determine the impact of not applying these practices on service delivery in South Africa.

\section{Acknowledgements Competing interests}

The authors declare that they have no financial or personal relationships that may have inappropriately influenced them in writing this article.

\section{Authors' contributions}

R.L. (University of Johannesburg) was the study leader and contributed to writing the article, whilst M.M. (University of Johannesburg) was responsible for project design, field research and also contributed to writing the article. 


\section{References}

Akinboade, O., Kinfack, E. \& Mokwena, M., 2012, 'An analysis of citizen satisfaction with public service delivery in the Sedibeng district municipality of South Africa', International Journal of Social Economics 39(3), 183-187. http://dx.doi. org/10.1108/03068291211199350

Amaratunga, D., Sarshar, M. \& Baldry, D., 2002, 'Process improvement in facilities management: The SPICE approach', Business Process Management Journal 8(4), 318-337. http://dx.doi.org/10.1108/14637150210434982

Auditor General, 2008, Performance audit of entities that are connected with government employees and doing business with national departments, viewed 07 September 2009, from http://db3sqepoi5n3s.cloudfront.net/files/ docs/090610entities_3.pdf

Baldwin, J., Orr, S. \& Simon, A., 1996, 'Procurement practices in the Australian wine industry', Journal of Wine Research 8, 3-13. http://dx.doi. org/10.1080/09571269708718093

Baron, A., 2011, 'Measuring human capital', Strategic HR Review 10(2), 31-34. http://dx.doi.org/10.1108/14754391111108338

Chi, K., Pun, K. \& Yeung, I., 2006, 'Development of an assessment system for supplier quality management', International Journal of Quality and Reliability Management 23(7), 745-762.

Defee, C. \& Stank, T., 2005, 'Applying strategy-structure-performance paradigm to the supply chain environment', The International Journal of Logistics Management 16(1), 29-41. http://dx.doi.org/10.1108/09574090510617349

Department of Public Service and Administration, 2007, Batho Pele handbook, viewed 03 June 2012, from http://www.dpsa.gov.za/batho-pele/docs/BP_HB_optimised.pdf

Goncalves, H., 2009, 'Proposal of a strategy model planning aligned to the balances scorecard and the quality environments', The Total Quality Management 21(5), 463-471.

Gray, A. \& Jenkins, B., 1993, 'Codes of accountability in the new public sector', Accounting, Auditing and Accountability Journal 6(3), 53-58. http://dx.doi. Accounting, Auditing and Accounta
org/10.1108/09513579310042560

Hazlett, S., Johnston, S. \& McAdam, R., 2011, 'Establishing ex ante public construction supply guidelines in the public procurement of schools' estate', International Journal of Public Sector Management 24(3), 258-265.

Hunsaker, K., 2009, 'Ethics in public procurement: Buying public trust', Journal of Public Procurement 9(3), 411-418.

Huque, A., 2011, 'Accountability and governance: Strengthening extra-bureaucratic mechanisms in Bangladesh', International Journal of Productivity and Performance Management 60(1), 59-74. http://dx.doi.org/10.1108/17410401111094312

International Transport Forum, 2008, 'Competitive interaction between airports, airlines and high-speed rail', Joint Transport Research Centre, Round Table, 02-03 October 2008, Paris.

Mehrjerdi, Y., 2009, 'Excellent supply chain management', Assembly Automation 29(1), 53-58. http://dx.doi.org/10.1108/01445150910929866
Mofolo, M. \& Smith, W., 2009, 'Making use of "batho pele" principles to improve service delivery in municipalities', Journal of Contemporary Management 6, 430-440.

National Treasury, 2003a, Supply chain management unit, viewed 01 September 2009, from http://www.treasury.gov.za/legislation/pfma/supplychain/

National Treasury, 2003b, General procurement guidelines, National Treasury, Pretoria, pp. 7-8.

National Treasury, 2004, Supply chain management: A guide for accounting officers/ authorities, viewed 20 April 2012, from http://www.treasury.gov.za/divisions/ ocpo/sc/Guidelines/SCM\%20Jan900-Guidelines.pdf

National Treasury, 2011, Guidelines on the implementation of demand management viewed 03 June 2012, from http://www.treasury.gov.za/divisions/ocpo/sc/ Circulars/Guidelines\%20on\%20the\%20Implementation\%20of\%20Demand\%20 Management.pdf

National Treasury, 2012, Implementation guidelines PPPFA regulations, viewed 25 May 2012, from http://www.treasury.gov.za/divisions/ocpo/sc/Circulars/ GUIDELINES\%20PPPFA\%20REGS\%20-\%206\%20JUNE\%202013.pdf

Novack, R., Dunn, S. \& Young, R., 1993, 'Logistics optimizing and operational plans and systems and their role in the achievement of corporate goals', Transportation Journal 32(4), 29-40

O'Regan, K., 2012, Stamping out corruption is everybody's business, viewed 20 April 2012, from http://www.corruptionwatch.org.za/content/stamping-outcorruption-everybody\%E2\%80\%99s-business-0

Pauw, J. \& Wolvaardt, J., 2009, 'Multi-criteria decision analysis in public procurement - A plan from the South', Politeia 28(1), 66-88.

Raymond,J.,2008, 'Benchmarking in publicprocurement', Benchmarking:AnInternationa Journal 15(6), 783-785. http://dx.doi.org/10.1108/14635770810915940

Republic of South Africa, 1996, The Constitution of the Republic of South Africa (Act No. 108 of 1996, as amended in 2003), Government Printers, Pretoria.

Republic of South Africa, 1999, Public Finance Management Act (Act No. 1 of 1999), Government Gazette 33059, Government Printers, Pretoria.

Schapper, P.R., Malta, J.V. \& Gilbert, D.L., 2006, 'An analytical framework for the management and reform of public procurement', Journal of Public Procurement 6(1/2), 1-26.

Shipley, R. \& Kovacs, J.F., 2008, 'Good governance principles for the cultural heritage sector: Lessons from international experience', Corporate Governance 8(2), 214228. http://dx.doi.org/10.1108/14720700810863823

Taylor, N., Fleisch, B. \& Shindler, J., 2008, 'Changes in education since 1994', Paper commissioned by the South African Office of the Presidency, Pretoria.

US Government Accountability Office, 2009, 'Framework for assessing the acquisition function at federal agencies', International Handbook of Public Procurement 27 69 , viewed n.d., from http://sate.gr/nea/international\%20handbook\%20of\%20 69 , viewed n.d., from
Public\%20Procurement.pdf

Zikmund, W., 2003, Business research methods, 7th edn., South-Western, Mason, pp. 110-426. 